\title{
0-6 ay çocuklarda gelişimsel kalça displazisi (GKD) tedavisi
}

\section{The treatment of developmental hip dysplasia (DDH) between 0-6 months of age}

\author{
Fuat Bilgili', Yavuz Sağlam² \\ ${ }^{1}$ İstanbul Üniversitesi İstanbul Tıp Fakültesi, Ortopedi ve Travmatoloji Anabilim Dalı, İstanbul \\ ${ }^{2}$ Bahçelievler Devlet Hastanesi, Ortopedi ve Travmatoloji Birimi, İstanbul
}

\begin{abstract}
Gelişimsel kalça displazisi (GKD) tedavisinde ana amaç konsantrik kalça redüksiyonu sağlamak ve bu redüksiyonu devam ettirebilmektir. Displazi tespit edilen ve instabilitesi olmayan hastalarda statik kalça ortezleri ile (kalça abduksiyon ortezi) matürasyonun sağlanması, desantralize ve/veya instabil kalçalarda ise dinamik kalça fleksiyon ve abduksiyon ortezi olan Pavlik bandajı ile tedaviye başlanması ilk seçenek olarak kabul edilmektedir. Eğer Pavlik uygulaması sonrasında üçüncü haftada USG kontrolünde redüksiyon sağlanamamış ise tedavide ısrarcı olunmaz, genel anestezi altında muayene, artrografi, kapalı redüksiyon ve human pozisyonunda alçılı tespite geçilmesi önerilmektedir.
\end{abstract}

Anahtar sözcükler: kalça displazisi, gelişimsel; Pavlik bandajı
To ensure concentric reduction of the hip, and to continue this reduction are the main goals in the treatment of developmental dysplasia of the hip (DDH). Static hip orthosis, such as hip abduction brace can be used in reduced and dysplastic hips to improve the maturation, whereas dynamic hip flexion and abduction orthosis, such as Pavlik harness can be used in decentralized hips for reduction, as a first choice. If the reduction cannot be ensured in the third week after the application of Pavlik, instead of continuing the treatment, closed reduction under general anesthesia with arthrographic evaluation and cast immobilization in human position is recommended.

Key words: hip dysplasia, developmental; Pavlik harness
G elişimsel kalça displazisi (GKD), doğumdan hemen sonra teşhis edilebilen ve başlangıçta femur başı asetabulum ilişkisinin bozulmadığı bir hastalıktır. Zamanla kalça eklemindeki yumuşak dokularda ve kemik dokularındaki patoloji dolayısı ile eklemde tam çıkıklar oluşmaktadır. Patoloji genellikle asetabulumdaki gelişim yetersizliğine bağı olduğundan ve zamanla oluştuğundan, yeni terminolojide doğumsal kalça çıkı̆̆ı (DKÇ) yerine gelişimsel kalça displazisi (GKD) kullanılmaya başlanmıştır. Eğer doğumda kalçanın çıkık olduğu tespit edilirse, "doğuştan” veya "konjenital" terimleri kullanılır. Konjenital çıkıklara sendromik hastalarda ve daha nadir olarak rastlanır.

GKD'de tedavinin ana amacı, konsantrik kalça redüksiyonu sağlamak ve bu redüksiyonu devam ettirebilmektir. Bu sayede asetabular gelişim de uyarılır, asetabular derinlik artar ve stabil redüksiyonun devamı sağlanabilir.

Doğum sonrasında ilk üç ayda yapılan kalça ultrasonografisinde (US) alfa $(\alpha)$ açısının $50-59^{\circ}$ arasında olması, fizyolojik gelişim geriliği (immatürite, Graf Tip Ila) ile ilişkilidir ve \%90-97 hastada spontan iyileşme gözlenir. ${ }^{[1-4]}$ Kendi kliniğimizde Tip Ila kalçalar üzerinde yaptığımız bir çalışmada, ortalama altıncı haftada yapılan kalça US'sinde $\alpha$ açısının 55,5'nin altında olmasının, displazinin devam etmesinin en önemli risk etmeni olduğunu tespit ettik. Doğumdan sonraki üçüncü ay dolduğunda $\alpha$ açısı halen $59^{\circ}$ veya daha düşük ise, matürasyon defektinden söz edilir (GrafTip IIb). Kalçanın redükte olduğu ve matürasyondaki hızlanmanın hedeflendiği bu durumun tedavisinde, kalça abduksiyon ortezi veya Mittelmeier-Graf ortezi gibi statik ortezler tercih edilir.

Desantralize tip kalçalarda (Tip III ve IV) ise dinamik fleksiyon ve abduksiyon sağlayan Pavlik bandaj uygulaması ile \%85-95 oranında kalça redüksiyonu sağlanır. ${ }^{[5]}$ Çocuğun yaşının büyük olması ( $>6$ ay), yumuşak doku kontraktürü ve asetabulumdaki sekonder değişiklikler, Pavlik bandajının başarı oranını azaltır. Labrumun inverte olduğu ve kalça redüksiyonuna ciddi engel teşkil

- İletişim adresi: Op. Dr. Fuat Bilgili, İstanbul Üniversitesi İstanbul Tıp Fakültesi, Ortopedi ve Travmatoloji Anabilim Dalı, Millet Caddesi, İstanbul Tel: 0212 - 4142000 e-posta: fuatbilgili@gmail.com

- Geliș tarihi: 3 Eylül $2014 \quad$ Kabul tarihi: 3 Eylül 2014 
ettiği tip desantralize kalçalarda (Tip IV) Pavlik bandajının başarı oranları \%50'lere kadar düşer. Üç haftalık Pavlik uygulaması ile redüksiyon sağlanır ise tedaviye Pavlik bandajı ile devam edilir. Eğer Pavlik uygulaması sonrasında üçüncü hafta US kontrolünde redüksiyon sağlanamamış ise tedavide ısrarcı olunmaz; genel anestezi altında muayene, artrografi, kapalı redüksiyon ve human pozisyonunda alçlı tespite geçilir $\left(95^{\circ}\right.$ fleksiyon ve $45^{\circ}$ abduksiyon). ${ }^{[6]}$ Redüksiyon nazik bir şekilde yapılmalıdır. Hatta, kalça $90-100^{\circ}$ fleksiyonda iken pasif abduksiyona getirildiğinde redükte olması beklenir. Redüksiyon için zorlamadan ve Ortolani manevrasından kaçınılır. Zorlu redüksiyonun femur başı avasküler nekrozu (FBAVN) oranlarını arttırdığı bilinmektedir.[7] Redüksiyonun olduğu abduksiyon derecesi ile redisloke olduğu abduksiyon derecesi arasındaki hareket açıklığı farkına, güvenli alan (Ramsey'in güvenli alanı) denir. ${ }^{[8]}$ Güvenli alanı arttırmak için adduktor tenotomi yapılabilir. Yine de güvenli bir redüksiyonun yapılamadığı olgularda açık redüksiyon sonrasında human pozisyonunda alçılama tercih edilebilir. Henüz femur başı ossifikasyon merkezinin oluşmamış olduğu grupta, açık redüksiyon ile FBAVN oranlarının ciddi şekilde arttığını savunan çalışmalar vardır. ${ }^{[9,10]}$ Pavlik bandajı uygulaması ile başarılı olunamayan hastalarda kapalı redüksiyon öncesi traksiyon uygulanması da tartışmalıdır. [11] Traksiyonun uygulama şekli ve süreci de ayrı bir tartışma konusudur. Traksiyonun tercih edildiği ekollerde yaklaşım genellikle, kalça iki hafta nötral pozisyonda, iki hafta da $90^{\circ}$ fleksiyonda traksiyon şeklindedir.

\section{Pavlik bandaj kullanımı ve dikkat edilmesi gereken hususlar}

Altı aydan küçük çocuklarda GKD'nin tedavisinde en sık kullanılan Pavlik bandajı kalçayı dinamik olarak fleksiyonda tutan ve adduksiyona gelmesini engelleyen bir ortezdir. Ana göğüs kayışı, omuz askısı ve ayakları içine alan iki banttan oluşur. Uygulaması diğer cihazlara göre nispeten zordur; ancak hastanın hastanede kalmasını gerektirmeyen ve çocuğun büyümesi ile gerekli değişikliklerin kolaylıkla yapılabildiği bir ortezdir. Pavlik bandajı 9-12 aya kadar uygulanabilir. Sadece çıkık kalçalarda değil, stabil olmayan (çıkabilen ve sublukse edilebilen) kalçalarda da stabiliteyi sağlamak amacı ile de kullanılabilir. ${ }^{[6,12]}$

Ayakta durabilen (genellikle 12 ay sonrası) çocuklarda, kalça $90-100^{\circ}$ fleksiyonda iken femur başının triradiat kıkırdağa santralize olmadığının düz röntgen ile tespit edildiği olgularda, artrogripozis gibi eklem kontraktürleri olan hastalarda, meningomiyelosel gibi kas dengesizliği olan çocuklarda, Down sendromu, osteogenezis imperfekta, Marfan sendromu gibi hastalıklarda ve enfeksiyon sonrası görülen çıkıklarda, Pavlik bandajı uygulaması sakıncalıdır. ${ }^{[13]}$
Pavlik bandajı çocuk supin pozisyonda yatarken uygulanır. Uygulama sırasında çocuğun üzerinde bezi haricinde kolsuz bir atlet ve diz üstüne kadar ulaşan bir çorap olması sağlanır. Öncelikle meme hizasından ana göğüs kayışları takılır (Şekil 1). Gögüs ile kayış arasında, üç parmak girebilecek kadar boşluk olmalıdır. Aksi takdirde çocuğun rahat nefes alması önlenmiş olur. Omuz askıları arkada çaprazlanarak ana kayışa bağlanmalıdır. Daha sonra ayaklara takılacak kayışlar uygulanır (Şekil 2). Ayak ve gögüs kayışlarının

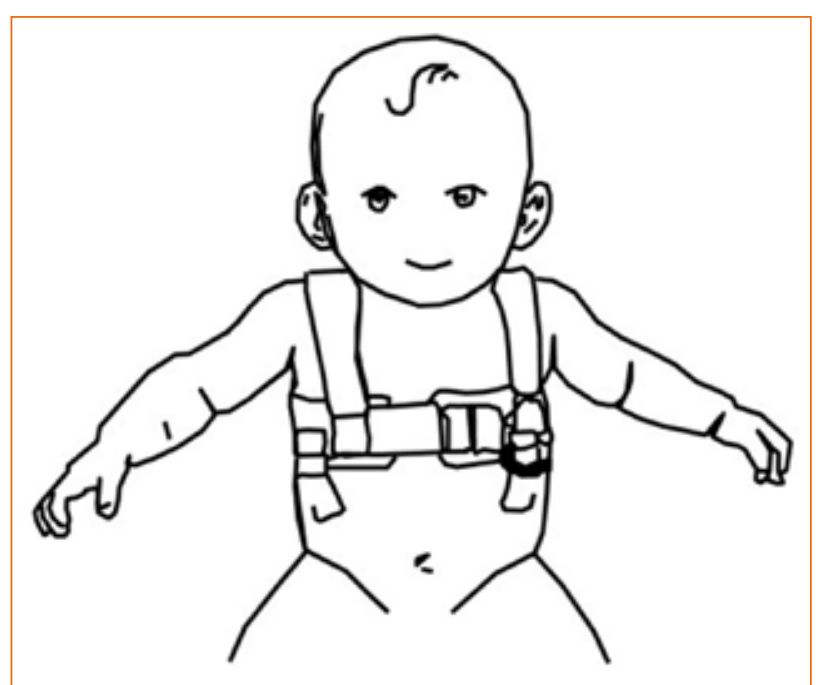

Şekil 1. Illk olarak meme hizasından ana göğüs kayışları takılır.

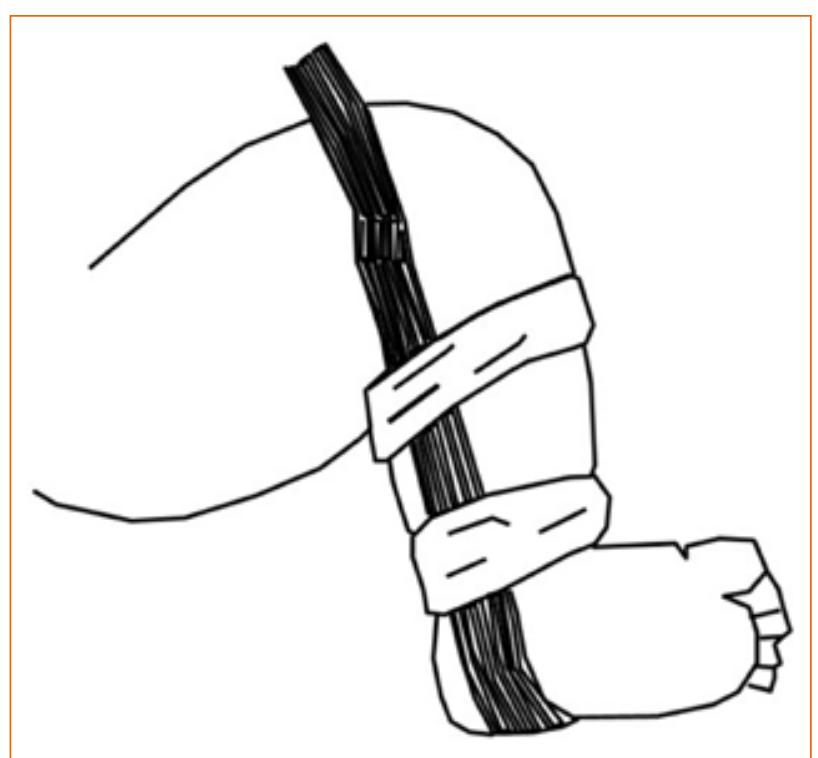

Şekil 2. İkinci basamakta ayak kayışları uygulanır. Ayağa uygulanan kayışlardan proksimaldeki popliteal bölgenin hemen altından, distaldeki ise ayak bileği ekleminin hemen proksimalinden uygulanır. 
bağlantısını yapan ön kayışlar kalçanın fleksiyona gelmesini sağlar ve $90-100^{\circ}$ arasında sabitlenir. Ön kayışlar her zaman dizin mediyalinden geçmeli ve bağlandığı toka ön aksiller çizgi hizasında olmalıdır (Şekil 3). Böylece kalçaların ekstansiyona gitmesi önlenir. Arka kayışlar ise abduksiyonu kontrol eder ve esas amaçları kalçaların $30^{\circ}$ 'den daha fazla adduksiyona gitmesini önlemektir (Şekil 4). Abduksiyon için bir zorlama yoktur, bacağın ağırlığı ile abduksiyon sağlanır. Dizler adduksiyona zorlandığında, dizler arasında $3-5 \mathrm{~cm}$ kadar

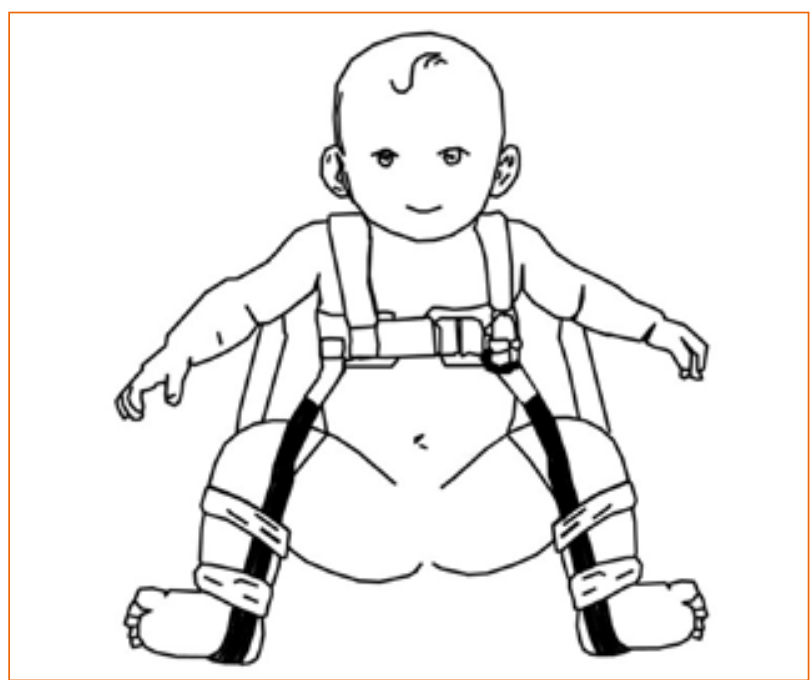

Şekil 3. Ayak ve göğüs kayışlarının birbirine bağlayan ön kayışlar kalçaları 90-100 fleksiyonda tutacak şekilde sabitlenir.

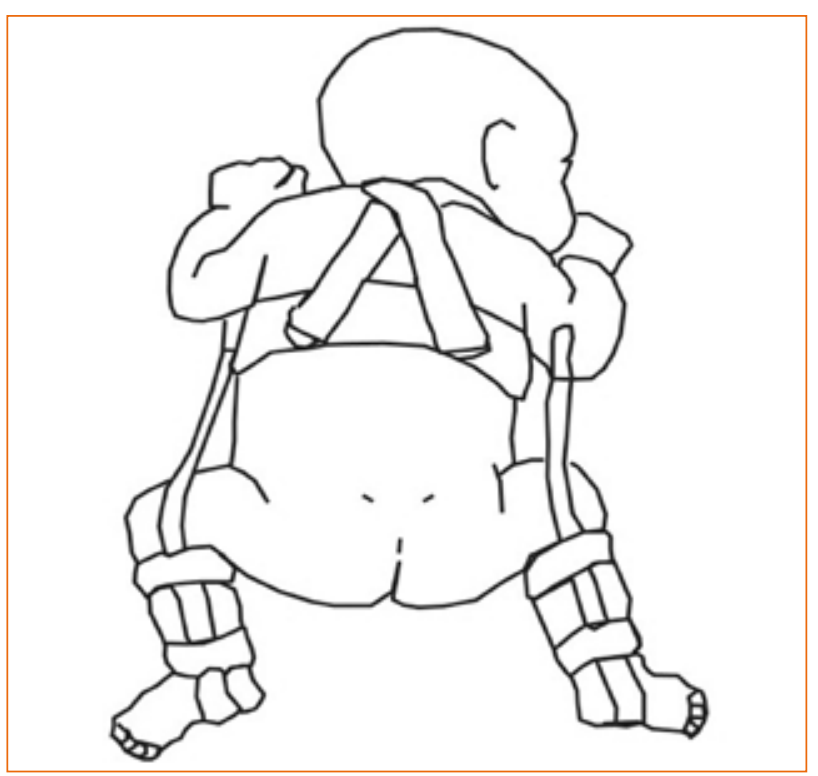

Şekil 4. Son olarak arka kayışlar kalçaların adduksiyona gitmesini önleyecek şekilde uygulanır. mesafe olmalıdır. Ardından çocuk prone pozisyona getirilerek trokanter majorlar arası bir asimetri olup olmadığı kontrol edilir. Bandaj uygulandıktan sonra, her iki kalçanın AP grafisi alınarak kalçaların fleksiyonunun yeterli olup olmadığı kontrol edilebilir. Ayrıca US ile de redüksiyon kontrolü yapılabilir. ${ }^{[14]}$

ilk uygulamayı hekim yapmalı, aileye bantların nasıl takıldığını ve hangi pozisyonda sabitlendiğini göstermelidir. Olabilecek komplikasyonlar hakkında aileye bilgi verilmeli, çocuğun uzun süre prone pozisyonda yatırılmaması anlatılmalıdır. Kalçada adduksiyon kontraktürü olan çocuklarda, bandaj uygulaması ile genellikle iki hafta içerisinde kontraktür açlır.

Pavlik tedavisinde bandajın üç hafta sürekli takılması ve üçüncü haftanın sonunda redüksiyonun US ile kontrolü önerilir. İlk uygulamadan 2-3 gün, bir hafta ve iki hafta sonra da muayeneler yapılarak bandajın uygun kullanılıp kullanılmadığı, çocuğun pozisyonunun doğru olup olmadığı kontrol edilmelidir. Eğer redüksiyon sağlanabilir ise, genellikle 4-6 hafta içerisinde stabil bir kalça eklemi elde edilir. Takip eden klinik muayenelerde Barlow testi yapılması önerilmez. Bu aşamadan sonra Pavlik kullanımı aşamalı olarak azaltılabilir. Altıncı haftadan sonra bandaj günde iki saat çıkarıı. Ardından, haftalık süreçlerde, bandaj günde 4, 6, 8 saat süreler ile çıkarılırve sonrasında gece ortezlemeye geçilir. Bandajın kullanım süresi altı haftadan kısa olmamakla birlikte, yaşa göre değişiklikler gösterebilir. ${ }^{[14]}$ Kalça stabilitesi kazanıldıktan sonra veya gece kullanıma geçileceği zaman kalça abduksiyon ortezi gibi, kullanımı daha rahat olan başka bir orteze geçilebilir. Ultrasonografik ve radyografik olarak kalçalar normale gelinceye kadar gece ortezlemesine devam edilmelidir. ${ }^{[5]}$ Radyolojik olarak asetabulum lateralinde görülen çentiklenme, gelişimsel kalça displazisinin başarılı tedavi sonucu göstergesidir (Şekil 5).

Pavlik bandajı uygulandıktan sonra üç hafta içinde halen çıkık devam ediyorsa, hasta yeniden ayrıntılı olarak değerlendirilmelidir. Çıkık superior, inferior, lateral ve posterior olabilir. Superior ise kalça fleksiyonu arttııılır, inferior ise azaltılır. Lateral çıkıklarda femur üst uç metafizi triradiat kıkırdağa yönelirse, zamanla konsantrik redüksiyon olabilir. ${ }^{[5]}$ Üçüncü hafta sonunda uygun bandaj kullanımına rağmen çıkık devam ediyorsa, başka tedavi metoduna geçilmelidir. ${ }^{[6,12,13,15,16]}$ Bandaj kullanımında ısrarcı olunursa asetabulum posterior duvar erozyonu (Pavlik hastalığı) meydana gelebilir. ${ }^{[17]}$

Kalça ileri derecede fleksiyona zorlanırsa obturator veya inferior çıkık meydana gelebilir. Ayrıca, hiperfleksiyonda femoral sinirin inguinal bağın altında sıkışması ile femoral sinir paralizisi meydana gelebilir. Bu durumda 


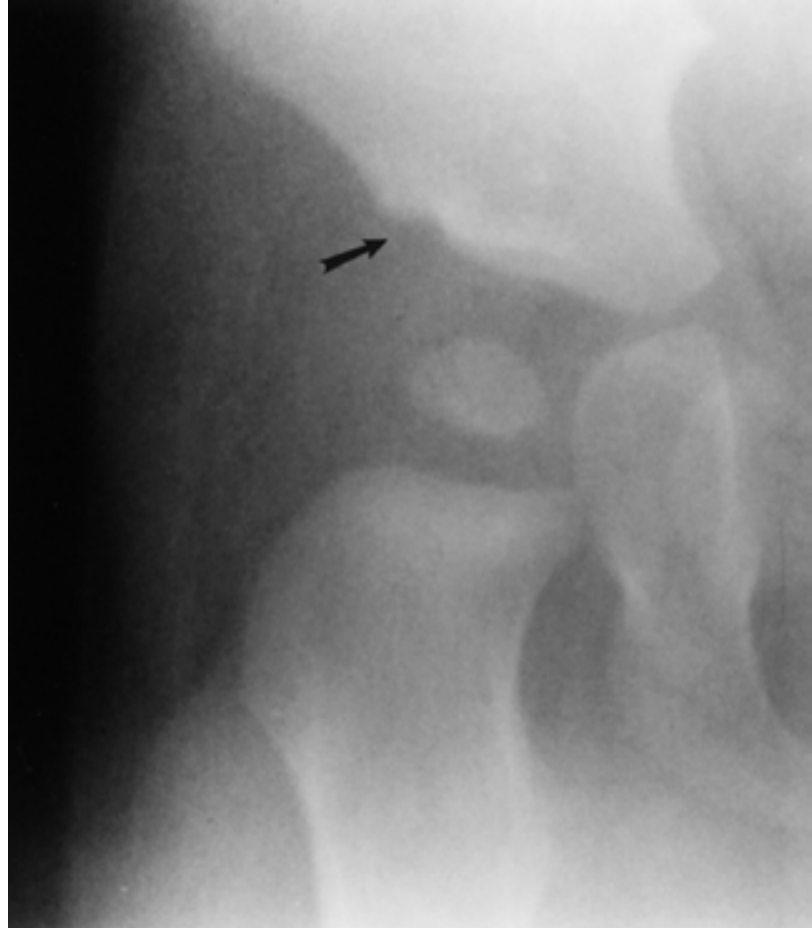

Şekil 5. Gelişimsel kalça displazisi olan yedi aylık bir bebeğin başarılı Pavlik tedavisi sonrası radyolojik görünümü. Asetabulumun lateral kenarındaki çentiklenme (ok) başarılı tedavinin göstergesi olarak labrum altında görülen ossifikasyonun bulgusudur (Tachdjian). çocuğun kuadriseps kasını aktif olarak kullanmadığı ve tekmeleme hareketini yapmadığı gözlenir. $\mathrm{O}$ takdirde Pavlik bandajı tedavisine ara verilmelidir. Genellikle femoral sinir felci geçicidir ve 3-5 gün içerisinde düzelme gözlenir. Düzelme olduğunda çocuk tekrar Pavlik içerisine konulabilir; ancak kalça fleksiyonu $100^{\circ}$ 'yi geçmemelidir. Femoral sinir geçici felcinin tedaviyi kötü yönde etkilediği gösterilmiş ve redüksiyon oranlarını azalttığı bildirilmiştir. ${ }^{[18]}$ Yine kalçanın aşıı fleksiyonunda omuz bantlarının çekmesine bağlı brakiyal pleksus geçici paralizileri de bildirilmiştir. ${ }^{[19]}$ Bandajın küçük olması, arka kayışların diz eklemini valgusa zorlamasına ve dizde mediyal insitabilite gelişmesine neden olabilir.

Pavlik tedavisi ile çeşitli FBAVN oranları literatürde belirtilmiştir. Santos ve arkadaşları, Pavlik ile tedavi ettikleri 149 kalçanın ortalama altı yıllık takipleri sonrasında (12-175 ay), 24 (\%16,1) kalçada FBAVN bildirmişlerdir. Harris ve arkadaşları ise Pavlik bandajı ile FBAVN oranlarını \%0,7 olarak bildirmişlerdir. ${ }^{[20,21]}$

GKD tedavisinde Pavlik kullanımıyla ilgili yapılan çaIışmaların özeti Tablo 1'de verilmiştir. ${ }^{[22-28]}$ GKD tedavisinde daha az sıklıkla kullanılan Rosen ateli ile ilgili yapılan çalışmalar ise Tablo 2'de özetlenmiştir. ${ }^{[29-34]}$

Literatürde Pavlik bandajını diğer tedavi metodlarıyla da karşılaştıran çalışmalar da yapılmıştır. Atar ve arkadaşları, randomize olmayan olgu serilerinde

Tablo 1. GKD tedavisinde Pavlik kullanımıyla ilgili yapılan çalışmaların özeti

\begin{tabular}{lcccc}
\hline Çalışmalar & Kalça sayısı (Çıkık kalça sayısı) & Başarı oranı (\%) & Avasküler nekroz oranı (\%) & Kanıt düzeyi \\
\hline Pavlik \& Peltier & $1912(632)$ & 84 & 0 & 4 \\
Wade ve ark. & $2481(1523)$ & 80,2 & 11,5 & 4 \\
& & 81,9 & 2.4 & 4 \\
Walton ve ark. & $123(43)$ & 90 & 2,38 & 4 \\
Cashman ve ark. & $546(118)$ & 96,7 & 0 & 4 \\
Grill ve ark & $3611(2519)$ & 92 & 5,4 & 4 \\
Johnson ve ark. & $91(20)$ & - & & 4
\end{tabular}

Tablo 2. GKD tedavisinde Rosen ateli kullanımıyla ilgili yapılan çalışmaların özeti

\begin{tabular}{lcccc}
\hline Çalışmalar & Kalça sayısı & Başarı oranı (\%) & Avasküler nekroz oranı (\%) & Kanıt düzeyi \\
\hline Finlay ve ark. & 81 disloke veya disloke edilebilir & 95 & Rapor edilmemiş & 4 \\
Fredensborg & 111 instabil kalça & 100 & 0,9 & 4 \\
Mitchell & 100 & 92 & Rapor edilmemiş & 4 \\
Heikkila & 180 & 99,4 & 0,6 & 4 \\
Wilkinson ve ark. & 26 & 100 & 2,38 & 4 \\
Lauge-Pederson ve ark. & 275 & 97,8 & Rapor edilmemiş & 3
\end{tabular}


redüksiyon ve avasküler nekroz oranları açısından Pavlik bandajı ile Frejka yastığını karşılaştırmışlardır. ${ }^{[35]}$ Başarısızlık oranı Pavlik bandajında \%12, Frejka yastığında \%10, avasküler nekroz oranı ise sırasıyla \%6 ve $\% 7$ bulunmuştur. Wilkinson ve arkadaşları, yenidoğan kalça displazisi tedavisiyle ilgili yapmış oldukları geriye dönük randomize olmayan çalışmalarında, Pavlik bandajı, Craig ateli ve Von Rosen atelini hiç atel kullanılmayan grupla karşılaştırmışlar, ${ }^{[33]}$ Von Rosen splintini radyolojik görünüm ve sekonder tedavi oranları açısından daha başarılı bulmuşlardır. Fakat bu çalışmada en fazla sayıda olan çalışma grubu 43 kalçadan oluşmaktadır ve araştırmacılar çok sayıda potansiyel kafa karıştırıcı etmen olduğunu bildirmişlerdir.

Mevcut literatür ışığında, her kliniğin tedavi akış şeması farklı olabilmektedir. Şekil 6 ve 7'de bizim kliniğimizin GKD tedavisinde uygulamış olduğu akış şeması $^{[36]}$ ile Ulusal GKD Akış Şeması ${ }^{[37]}$ verilmiştir. Ayrıca

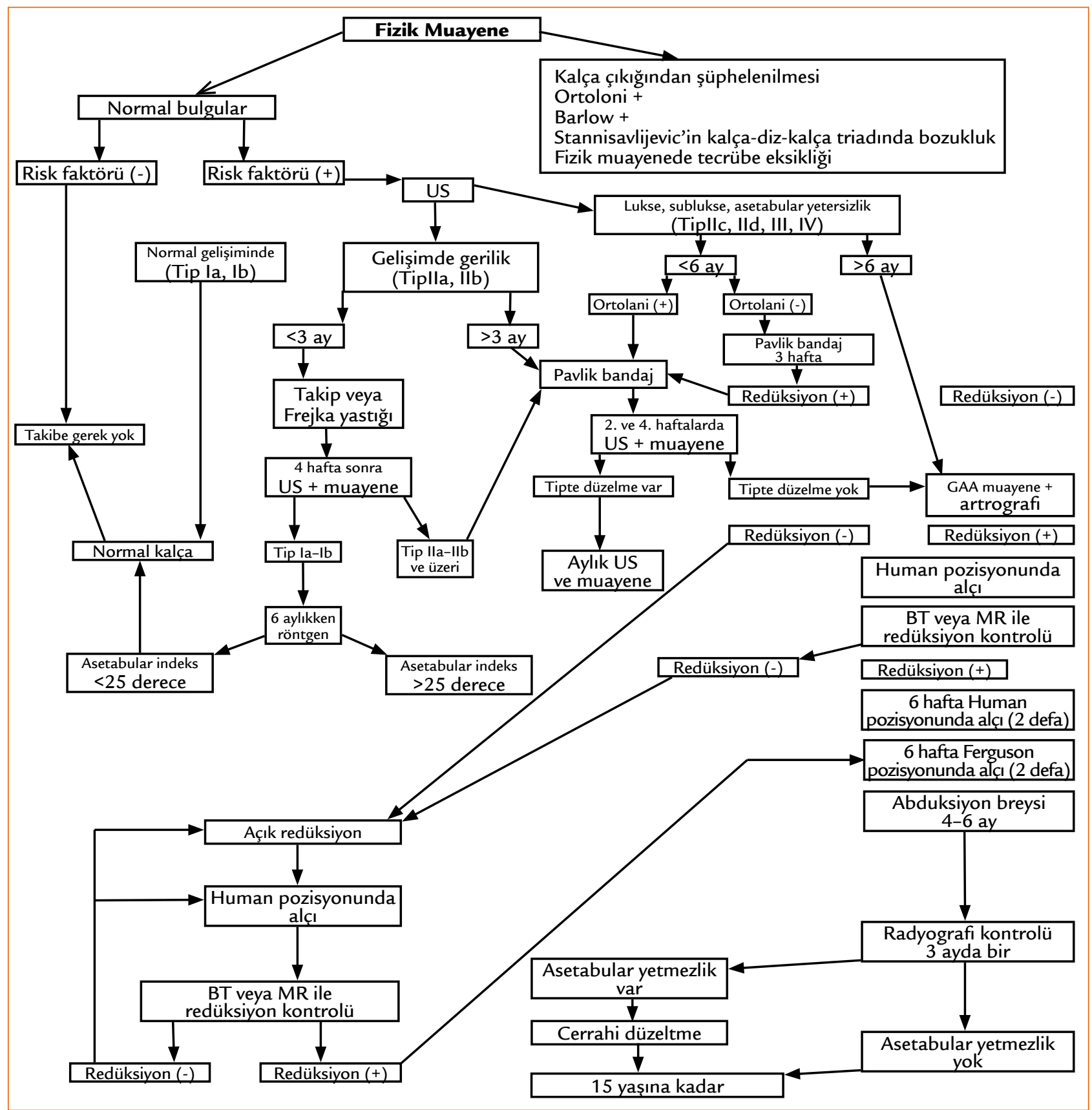

Şekil 6. GKD tedavisinde İstanbul Tıp Fakültesi tedavi akış şeması. 


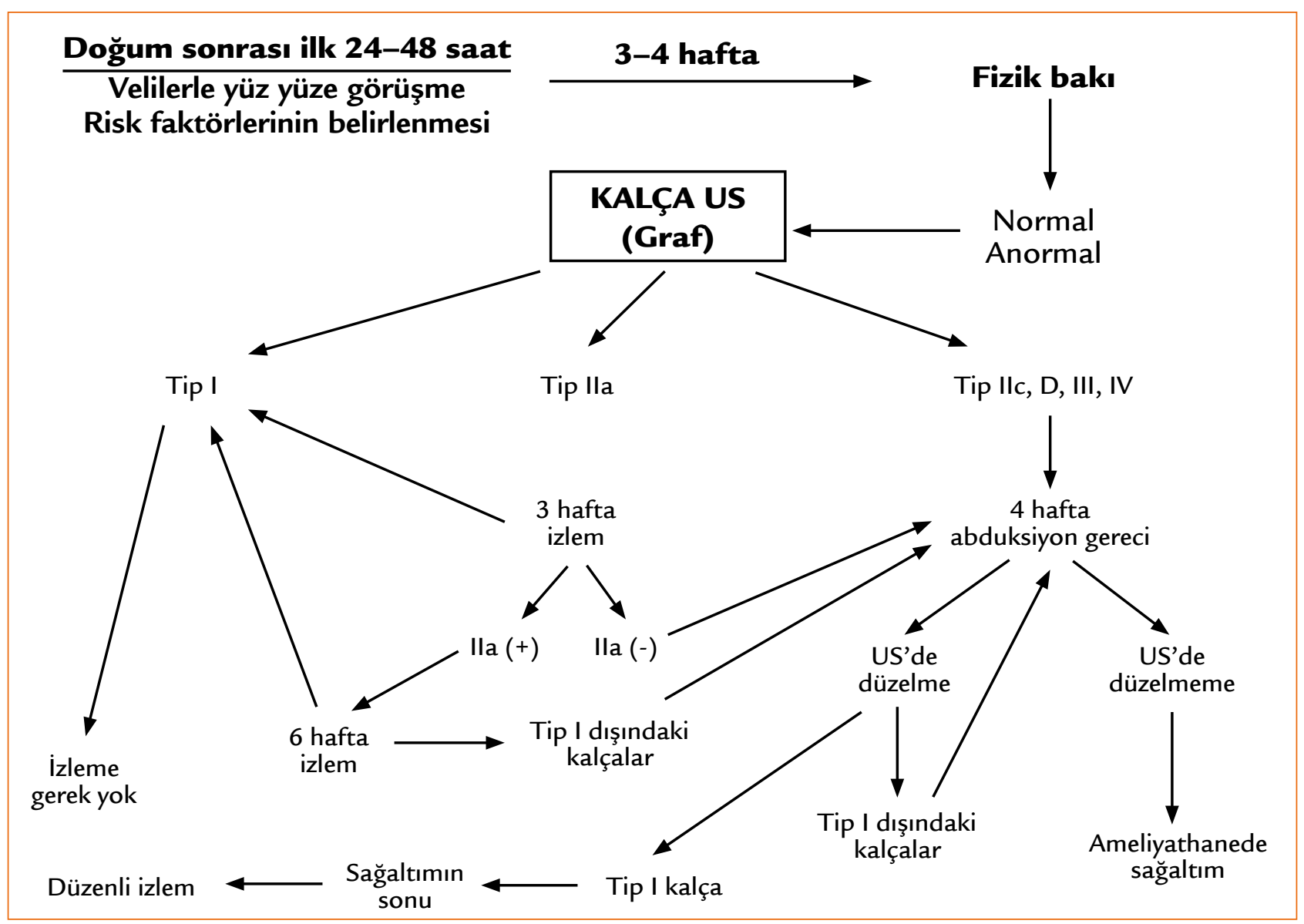

Şekil 7. GKD tedavisinde ulusal akış şeması.

Pavlik bandajı uygulamasıyla ilgili internette eğitici videolar bulunmaktadır. ${ }^{[38]}$

Sonuç olarak, GKD'nin erken tanı ve tedavisi sakatlık oranlarını ciddi şekilde azaltır. Displazi tespit edilen ve instabilitesi olmayan hastalarda statik kalça ortezleri ile (kalça abduksiyon ortezi veya Mittelmeier-Graf ortezi) matürasyonun sağlanması, desantralize ve/veya instabil kalçalarda ise dinamik kalça fleksiyon ve abduksiyon ortezi olan Pavlik bandajı ile tedaviye başlanması ilk seçenek olarak kabul edilir.

\section{KAYNAKLAR}

1. Graf R. Hip sonography: Diagnosis and Management of Infant Hip Dysplasia, 2nd ed.. Berlin: Springer; 2006.

2. Omeroğlu H, Caylak R, Inan U, Köse N. Ultrasonographic Graf type lla hip needs more consideration in newborn girls. J Child Orthop 2013;7(2):95-8. CrossRef

3. Roovers EA, Boere-Boonekamp MM, Mostert AK, Castelein $\mathrm{RM}$, Zielhuis GA, Kerkhoff TH. The natural history of developmental dysplasia of the hip: sonographic findings in infants of 1-3 months of age. J Pediatr Orthop B 2005;14(5):325-30.
4. Rosendahl K, Toma P. Ultrasound in the diagnosis of developmental dysplasia of the hip in newborns. The European approach. A review of methods, accuracy and clinical validity. Eur Radiol 2007;17(8):1960-7.

5. Kabukçuoğlu Y. Gelişimsel kalça displazisinin pavlik bandajı ile tedavisi. In: Temelli Y, Göksan SB, editörler. Gelişimsel kalça displazisi. İstanbul: TOTDER; 2007. p.23-8.

6. Guille JT, Pizzutillo PD, MacEwen GD. Development dysplasia of the hip from birth to six months. J Am Acad Orthop Surg 2000;8(4):232-42.

7. Roposch A, Ridout D, Protopapa E, Nicolaou N, Gelfer Y. Osteonecrosis complicating developmental dysplasia of the hip compromises subsequent acetabular remodeling. Clin Orthop Relat Res 2013;471(7):2318-26. CrossRef

8. Ramsey PL, Lasser S, MacEwen GD. Congenital dislocation of the hip: use of the Pavlik harness in the child during the first six months of life. J Bone Joint Surg Am 2002;84-A(8):1478.

9. Gardner RO, Bradley CS, Howard A, Narayanan UG, Wedge $\mathrm{JH}$, Kelley SP. The incidence of avascular necrosis and the radiographic outcome following medial open reduction in children with developmental dysplasia of the hip: a systematic review. Bone Joint J 2014;96-B(2):279-86. CrossRef 
10. Pospischill R, Weninger J, Ganger R, Altenhuber J, Grill F. Does open reduction of the developmental dislocated hip increase the risk of osteonecrosis? Clin Orthop Relat Res 2012;470(1):250-60. CrossRef

11. Burian $M$, Dungl $P$, Chomiak J, Ošt'ádal $M$, Frydrychová $M$. Efficiency of conservative treatment by overhead traction in developmental dysplasia of the hip. Acta Chir Orthop Traumatol Cech 2010;77(5):371-7.

12. Harding MG, Harcke HT, Bowen JR, Guille JT, Glutting J. Management of dislocated hips with Pavlik harness treatment and ultrasound monitoring. J Pediatr Orthop 1997;17(2):189-98.

13. Weinstein SL. Developmental hip dysplasia and dislocation. In: Lovell WW, Winter RB, Morrssy RT, Weinstein SL. Lovell and Winter's Pediatric Orthopaedics. 6th ed. Volume 1. Section 24. 2006. p.1007.

14. Kalamchi A, MacFarlane R 3rd. The Pavlik harness: results in patients over three months of age. J Pediatr Orthop 1982;2(1):3-8.

15. Herring JA. Conservative treatment of congenital dislocation of the hip in the newborn and infant. Clin Orthop Relat Res 1992;(281):41-7.

16. Tiruveedhula M, Reading IC, Clarke NM. Failed Pavlik Harness Treatment for DDH as a Risk Factor for Avascular Necrosis. J Pediatr Orthop 2014. [Epub ahead of print]

17. Millis MB, Kocher MS. Hip, pelvis, femur: Pediatric Aspect. In: Koval KJ, editor. Orthopedic Knowledge Update 7. Chicago: American Academy of Orthopaedic Surgeons; 2002. p.387-94.

18. Murnaghan ML, Browne RH, Sucato DJ, Birch J. Femoral nerve palsy in Pavlik harness treatment for developmental dysplasia of the hip. J Bone Joint Surg Am 2011;93(5):493-9. CrossRef

19. Mooney JF 3rd, Kasser JR. Brachial plexus palsy as a complication of Pavlik harness use. J Pediatr Orthop 1994;14(5):677-9.

20. Mafalda Santos M, Filipe G. Treatment of congenital hip dislocation using Pavlik's harness. Long term results. Rev Chir Orthop Reparatrice Appar Mot 1997;83(1):41-50.

21. Harris IE, Dickens R, Menelaus MB. Use of the Pavlik harness for hip displacements. When to abandon treatment. Clin Orthop Relat Res 1992;(281):29-33.

22. Pavlik $A$. The functional method of treatment using a harness with stirrups as the primary method of conservative therapy for infants with congenital dislocation of the hip. 1957. Clin Orthop Relat Res 1992;(281):4-10.

23. Wada I, Sakuma E, Otsuka T, Wakabayashi K, Ito K, Horiuchi O, Asagai Y, Kamegaya M, Goto E, Satsuma S, Kobayashi D, Saito S, Taketa M, Takikawa K, Nakashima Y, Hattori T, Mitani S, Wada A. The Pavlik harness in the treatment of developmentally dislocated hips: results of Japanese multicenter studies in 1994 and 2008. J Orthop Sci 2013;18(5):749-53. CrossRef
24. Walton MJ, Isaacson Z, McMillan D, Hawkes R, Atherton WG. The success of management with the Pavlik harness for developmental dysplasia of the hip using a United Kingdom screening programme and ultrasound-guided supervision. J Bone Joint Surg Br 2010;92(7):1013-6. CrossRef

25. Cashman JP, Round J, Taylor G, Clarke NM. The natural history of developmental dysplasia of the hip after early supervised treatment in the Pavlik harness. A prospective, longitudinal follow-up. J Bone Joint Surg Br 2002;84(3):41825. CrossRef

26. Grill F, Bensahel H, Canadell J, Dungl P, Matasovic T, Vizkelety T. The Pavlik harness in the treatment of congenital dislocating hip: report on a multicenter study of the European Paediatric Orthopaedic Society. J Pediatr Orthop 1988;8(1):1-8.

27. Johnson $\mathrm{AH}$, Aadalen RJ, Eilers VE, Winter RB. Treatment of congenital hip dislocation and dysplasia with the Pavlik harness. Clin Orthop Relat Res 1981;(155):25-9.

28. Filipe G, Carlioz H. Use of the Pavlik harness in treating congenital dislocation of the hip. J Pediatr Orthop 1982;2(4):357-62.

29. Finlay HV, Maudsley RH, Busfield PI. Dislocatable hip and dislocated hip in the newborn infant. $\mathrm{Br}$ Med J 1967;4(5576):377-81

30. Fredensborg $\mathrm{N}$. The results of early treatment of typical congenital dislocation of the hip in Malmö. J Bone Joint Surg $\mathrm{Br}$ 1976;58(3):272-8.

31. Mitchell GP. Problems in the early diagnosis and management of congenital dislocation of the hip. J Bone Joint Surg $\mathrm{Br}$ 1972;54(1):4-12.

32. Heikkilä E. Comparison of the Frejka pillow and the von Rosen splint in treatment of congenital dislocation of the hip. J Pediatr Orthop 1988;8(1):20-1.

33. Wilkinson AG, Sherlock DA, Murray GD. The efficacy of the Pavlik harness, the Craig splint and the von Rosen splint in the management of neonatal dysplasia of the hip. A comparative study. J Bone Joint Surg Br 2002;84(5):716-9.

34. Lauge-Pedersen H, Gustafsson J, Hägglund G. 6 Weeks with the von Rosen splint is sufficient for treatment of neonatal hip instability. Acta Orthop 2006;77(2):257-61. CrossRef

35. Atar D, Lehman WB, Tenenbaum Y, Grant AD. Pavli harness versus Frejka splint in treatment of developmenta dysplasia of the hip: bicenter study. J Pediatr Orthop 1993;13(3):311-3.

36. Demirhan M, Dikici F, Eralp L, Onen M, Göksan B. A treatment algorithm for developmental dysplasia of the hip for infants 0 to 18 months of age and its prospective results. Acta Orthop Traumatol Turc 2002;36(1):42-51.

37. Köse N, Ömeroğlu H, Dağlar B. Gelişimsel Kalça Displazisi Ulusal Erken Tanı ve Tedavi Programı 2010.

38. MubarakSJ. Pavlik Harness Application and Care in Older Male Infant. http://www.youtube.com/watch?v=MsV7cGrWpJU 